pebble, which I cast in passing upon your monument of fame. But, should it be the means of preventing one unnecessary or pernicions nephrectomy, or preserve to one poor wretch the internal secretion of his testicles, neither your bequest nor my labours will have been expended quite in vain.

REFERENCES.

1 Provincial Med, and Surg. Journ., 1845. 2 Ibid. ${ }^{3}$ Lancet, 184E. 4 Ibid. 1834. 5 Oracle, 1844. 6 Archiv fiir klin. Chirurgie v. Langenbeck, vol 1xxili, 1904, p. 277. 7 Immunity in Infective Diseases, Cambridge, 1905, p. 46. 8 Third Annual Report of the Henry Phipps Institute, p. 259 p. 1218. 11 Journal of Experimental Medicine,-"September, 1907.

\section{A NOTE ON NEPHROPEXY.}

BY BILTON POLLARD, B.S., F.R.C.S., SURGEON TO UNIVERSITY COLLEGE HOSPITAL.

THE interesting description which $\mathrm{Mr}$. Billington has given of a method of nephropexy prompts me to describe a somewhat slmilar though less elaborate operation which for ten years I regularly taught in $\mathrm{my}$ class of operative surgery at University College, and from time to time perform in hospital and private practice with most satisfactory results.

The princlple of the operation is to support the kidney by means of a sling fashioned from part of its capsule, additional support being ultimately obtained by the union of thedecapsulated surface of the kidney with the posterior wall of the abdomen.

The operation is performed as follows:-The patient having been placed on her side with a pillow beneath the loin, the kidney is exposed by an oblique incision commencing at the outer border of the erector spinae muscle about $\frac{1}{2}$ in. below the last rib, and running forwards and downwards parallel with the rib for 4 or 5 in. The latissimus dorsi and obliquns externus muscles are separated from one another and retracted, and the lumbar aponeurosis is divided in the line of the skin inclsion. The kidney is then shelled out of its fatty capsule, and brought out of the wound. Two incisions are thereupon made In its fibrous capsule in the following manner: First, from a point on the outer border of the kidney, a little below the upper pole, an incision is carried obliquely over the posterior surface of the kidney to the lower part of the hilum; secondly, an incision starting from the same point Is carried along the anterior surface of the organ, but parallel to the outer border, at a distance of about half an inch from it, and prolonged like its fellow to the level of the lower part of the hilum. The triangular flap thus outlined is peeled off the kidney, but is left attached along its lower border or base. If any part of the quadratus lumborum muscle projects beyond the outer border of the erector spinse, it is divided, and the latissimus dorsi and obliquas externus muscles are thoroughly separated from one another, and retracted at the upper part of the wound so as to expose the upper part of the lumbar fascia, together with the lower two ribs and the intervening intercostal muscle. The [kidney is now dropped back into position, but not into Its fatty capsule, which has been allowed to fall towards the middle line and lie about the renal pedicle. The flap of the fibrous capsule, held for the time by a couple of forceps, is utilized to raise and hold the kidney so that its decapsulated surface is drawn up beneath the ribs and comes to rest against the anterlor or deep surface of the lumbar fascia, the external arcuate ligament, and the diaphragm; the flap is itself spread out, and is stitched along its borders to the outer surface of the lowest intercostal muscle and the portion of the lumbar fascis which intervenes between the wound in the fascia and the last rib. The kidney is thus suspended by a broad triangular ligament, made out of its own capsnle, which is continuous with the part of the capsule lelt attached to the lower third of the kidney.

Further support is gained by a couple of stitches which fasten the lower third of the kidney to the lumbar fascia. The wound is finally stitched up in layers and completely closed. The material used for the buried stitches is silk, and for those in the skin silkworm gat and horsehair.

\section{PERICOLITIS SINISTRA WITH ABSCESS FORMATION : RECOVERY.}

By ROBERT DONALDSON, M.A., M.B., CH.B EdiN., LATE SENIOR HOUSE-SURGEON, ROYAL SOUTHERN HOSPITAL, LIVERPOOL.

SRVEraI cages of pericolitis have been investigated during recent years, and it bas ceased, therefore, to be regarded as of rare occurrence, but a detailed description of it has not yet found its way into the majority of English textbooks. The following case, therefore, which came under my notice recently, will be of interest as illustrating the condition in a fairly ty pical manner.

The patient, a marine engineer, oged 44, came complaining that ho was suffering from an attack of malaria He had returned only a few deys previously from South Africe, where he had been resident some ten years, and, while working outof-doors insufficiently clad, had caught a chill. This ushered in what appeared to him to be a return of malarial fever, the symptoms of which he was thoroughly cognizant of from past experience.

Previous History.

About the age of 18 he contracted gonorrhoea. Six years ago, while resident in Natal, he began to suffer from bilharziosis. The acute stage of this cilsease lasted nearly a year, but he continued to be troubled in a slighter degree for the next four years, when he became apparentily cured. Since then he has had no recurrence. It is interesting to note this in passing, for it is not an everyday occurrenco to meet with a oure in for it is not an everyday occurrence to meet with a care in a person who has acquired the disease in adult life. The parasite in this instance appears to have been confined to the genito-urinary tract, as the patient never bad any symptoms of bowel irritation. Five years ago he had syphilis, for which at first he was not treated. Eighteen months ago he had his first attack of malaria, since when he has had several attacks at intervals. He has suffered all his life from chronic constipation, and this fact has an important bearing on the course of events in this case. The bowels, he sald, were never moved save at intervals ranging from three to six days. Apart from this idlosyncrasy he has never had any other bowel trouble.

Condition when First Seen.

The patient was seen on the day following the supposed attack of malaria. He was a thin, rather cacheotic-looking attack of malaria. He was a thin, rather cacheotic-looking man. The spleen was slightly enlarged, but there appeared to be nothing in his condition to lead one to suppose he was suffering from other than an attack of malaria. The blood was
unfortunately not examined for parasites, but he was at once put on a course of quinine.

\section{After-History.}

He appeared better for a day or two, when suddenly a fresh He appeared better for a day or two, when suddenly a iresh obstinate in splte of the repeated administration of aperients by the mouth, ceased to act, and he was quite unable to pass flatus. His tongue was thickly costed and dry. He was seized with frequent vomiting, and complained of evere abdominal pain, which seemed to come on in spasms. The temperature was subnormal, but the pulse, which was rather small, was over 100. He lay with the legs drewn up in bed; the abdomen was uniformly distended, the muscles were on guard, and there was an was an absence of movement of the abdominal ion. A condition of general tenderness was present on palpation, and a tympanitic note was elicited all over. Liver dullness was diminished. Turpentlne stupes were applied locally, and enemata were ordered with a view to clearing out the large bowel. They, however, had absolutely no effect, and as the day wore on the patiert's distress became more evident. The romiting became constant ; there was an increase of pain greater abdominal distenslon, and a weaker and more rapld pulse ; In short, all the signs and symptoms of acute obstraction. Where the obstruction was, or of what nature, it was impossible to say.

Preparations were accordingly made for immediate operation when as result of snother enema, the patient passed somo faeces and 8 large amount of flatus. It was decided, therefore, to adopt an expectant attitude, with a vlew to determining, if possible, the site of nbstruction. There now followed a temporary general amelioration of the symptoms. The vomiting ceased, and by means of operlents and enemats the bowels were kept acting. The abdomen, however, remained distended, though not to the same extent. There was still a significant lack of movement of the abdominal wall. The patient still pationt still complained of general abdomina pain and disover no area could be singled ont as being more tender than another. The tongue was dry, fissured, and thickly costed, and the pulse was small and about 100 .

The patient remained more or less in this condition for some days, during which time he rapidly lost flesh, and became considerably weaker. Except for the initial rise of temperature at the commencement of his illness, the temperature bad been normal all the time, but about the ninth day from the 